\title{
Trends of Maternal Mortality in Nineveh (2004-2013), A Time Series Analysis
}

\author{
Najlaa I M Al-Sammak, Humam G I Zubeer \\ Department of Family and Community Medicine, College of Medicine, University of Mosul, Mosul, Iraq. \\ Correspondence: Najlaa Ibrahim Mahmood. Najlaaalsammak@gmail.com.
}

(Ann Coll Med Mosul 2018; 40 (2): 41-47).

Received: $8^{\text {th }}$ May 2018; Accepted: 28 $^{\text {th }}$ Oct. 2018.

\section{ABSTRACT}

Context: Maternal Mortality is a worldwide issue that serves as a visible health indicator of a nation's health care system. As part of the $5^{\text {th }}$ Millennium Development Goal, the UN established the target of reducing maternal mortality by three-quarters between 1990 and 2015 for all national and regional populations.

Aim: Determine the trend of maternal mortality in Nineveh for 10 year period (2004-2013).

\section{Subjects and methods}

Study design: Descriptive biometric study design.

Study settings: Nineveh Governorate/North of Iraq.

Study sample: Maternal deaths, women at childbearing age, and live births from 2004 to 2013.

Data collection tool: Death certificates, vital registration system.

Outcome measures: Maternal mortality rate, ratio, and life time risk of maternal death, stages of maternal mortality, in addition to their mortality causes and trends by using various rates, ratios, proportions, and Chisquared test for trend.

Results: Maternal mortality ratio changed significantly $(\mathrm{p}=0.002)$ during the study period being worst in 2007 (45.01/100,000 live birth). On average, about 1:666 women at childbearing age died either due to direct causes predominated by hemorrhage or indirect ones mainly CVDs.

Conclusions and Recommendations: Maternal mortality still a major problem that should be addressed carefully through facilitating women's accessibility to maternity services to save their lives.

Keywords: Maternal mortality, trend, Nineveh.

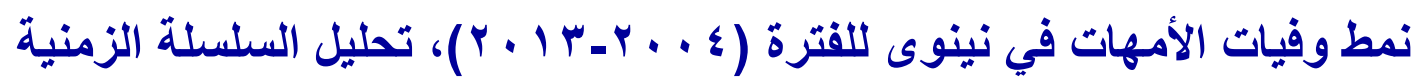

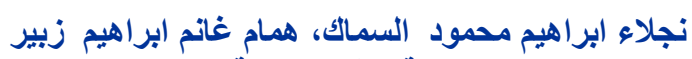

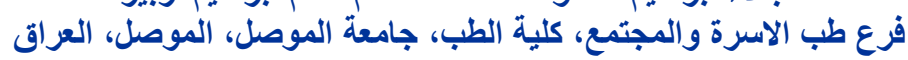

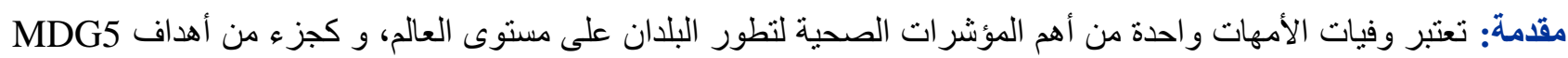

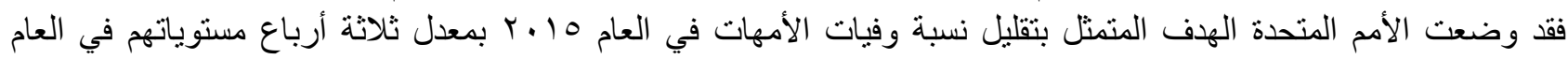

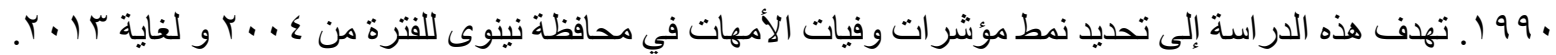

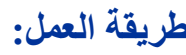

$$
\begin{aligned}
& \text { تصميم الدراسة: در اسة البايومتري الوصفية. }
\end{aligned}
$$

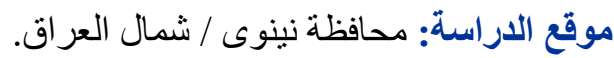

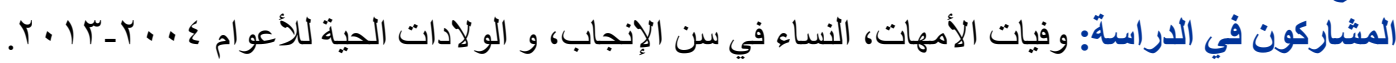

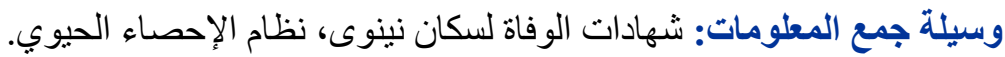




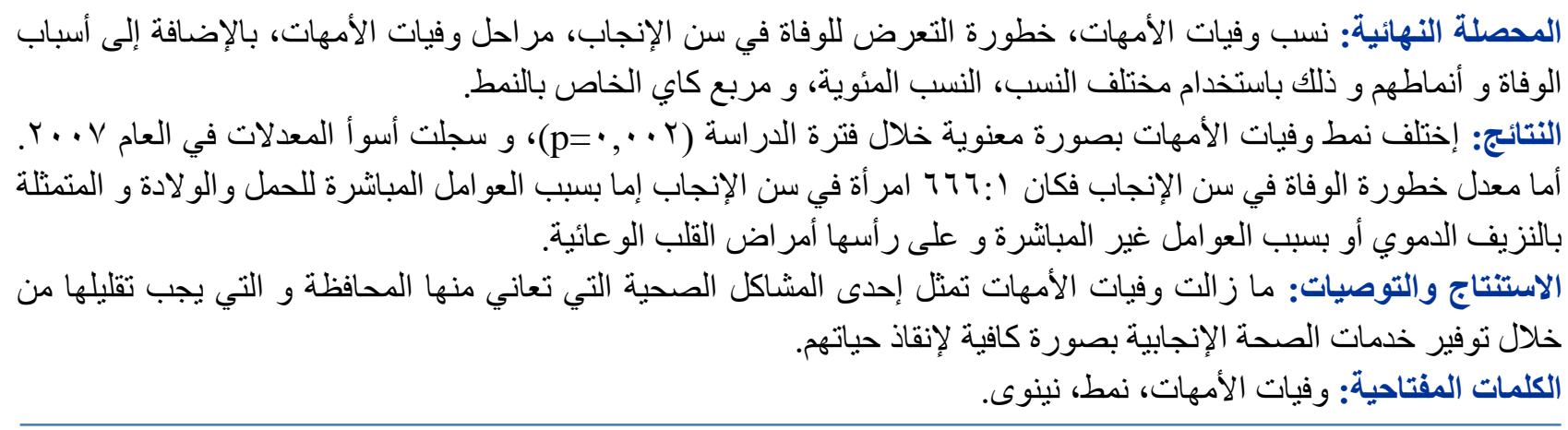

\section{INTRODUCTION}

$\mathrm{M}$ aternal mortality is one of the most important indicators that reflects the socioeconomic and health statuses of any country, that is why the United Nations made the reduction in maternal mortality one of its goals and established the target of reducing maternal mortality by three-quarters between 1990 and 2015 as part of the $5^{\text {th }}$ Millennium Development Goal (MDG5) ${ }^{1}$.

Maternal mortality is the death of a woman while pregnant, or within 42 days of termination of pregnancy irrespective of the duration or site of the pregnancy from any cause related to, or aggravated by the pregnancy or its management and not from accidental causes ${ }^{2,3}$. Late maternal death is the death from direct or indirect obstetric causes, more than 42 days, but less than one year after termination of pregnancy ${ }^{4}$.

The WHO defines maternal mortality rate as the number of maternal deaths due to complications of pregnancy, labour and the puerperium in a year $\times$ 1000 divided by total women (15-49 years) in the same year. The same agency describes maternal mortality ratio as the number of maternal deaths $x$ 1000 divided by total number of live birth in the same year ${ }^{2,3}$.

Another indicator used to assess maternal mortality is the life time risk of maternal mortality which takes into account both the probability of becoming pregnant and the probability of dying as a result of pregnancy cumulated across a woman's reproductive years. It can be measured by multiplying maternal mortality rate $\times 35$ which is the woman's reproductive years ${ }^{1}$.

Globally, maternal mortality ratio in 2005 was ranging between 1 in Ireland to 2100 in Sierra Leone for every 100,000 live births. In Iraq, it was $300 / 100000$ live births, a ratio considered high if compared with all adjacent countries including
Kuwait, Saudi Arabia, Turkey, Jordon, Syria, and Iran with maternal mortality ratios of 4, 18, 44, 62, 130 , and $140 / 100,000$ live births respectively ${ }^{5}$. Thus, too many women still die every day in the process of giving new life, most of these deaths could be prevented by improving access to health services and better trained, qualified, and more numerous staff especially in developing regions ${ }^{6}$. In most developing countries, the major medical causes of maternal mortality are hemorrhage, hypertensive diseases of pregnancy and various types of maternal infections ${ }^{7}$. Whereas in USA, there is a dramatic reduction in these causes but what emerged were underlying or worsening medical conditions such as $\mathrm{CVDs}^{8}$. The same figure was explored by $\mathrm{WHO}$ and the Institute for Health Metrics and Evaluation ${ }^{9}$ when they published a comprehensive analysis of maternal mortality causes and disclose that there is a striking increased importance of indirect causes of maternal death as a result of successful addressing of direct complications of pregnancy and childbirth.

Aim of the Study: To determine the trends of maternal mortality in Nineveh Governorate for 10 year period (2004-2013).

\section{SUBJECT AND METHODS}

\section{Ethical Consideration and Study Setting}

Administrative agreements and ethical consideration were obtained from the Ethical and Research Committee in Mosul College of Medicine, followed by formal agreement from Nineveh Health Directorate that in turn provided official permissions directed to all study settings involved in this work. 


\section{Study Setting}

This research was done in Nineveh, the $2^{\text {nd }}$ most populated governorate in Iraq after Baghdad with a total population approximating three and half million. The registered crude birth rate equal to 43.4/1000 midyear population and crude death rate approaching 3.6/1000 midyear population with $4 \%$ growth rate $^{10}$. Mortality data were obtained from vital registration system/ Statistical Department/ Nineveh Health Directorate in addition to the Public Health Center.

\section{Study Design}

Descriptive biometric study design which involves the analysis of routinely available data such as vital registration system to provide valuable information at local or national level (11), then followed by time series analysis.

\section{Study Sample}

The sample of this study included all maternal deaths and all alive women at childbearing age (15-49 years) in addition to the live births for 10 year period.

\section{Data Collection Tool and Duration of the Study}

In the absence of relevant census information, vital registration data were used which depend on death certificate. The duration of performing this research last from $1^{\text {st }}$ January 2018 to $1^{\text {st }}$ June 2018.

\section{Outcome Measures and Statistical Analysis}

To achieve the aim of the study, the following measures are used ${ }^{1,2,3}$ :

No. of maternal deaths (preg., labor and puerp.)

1. MM Rate $=\frac{\text { in a specific year }}{\text { Total no. of women (15-49y) in the same year }} \times 100000$

[Note: the proportion of women at childbearing age is $22 \%{ }^{12}$. No. of maternal deaths (preg., labor and puerp.)

2. $M M$ Ratio $=\frac{\text { in a specific year }}{\text { Total no. of LB in the same year }} \times 100000$

Life time risk of maternal death $=$ maternal mortality rate $\times 35$ [Note: 35 represents women's reproductive years]

$$
\text { 3. Proportion of MM by cause }=\frac{\begin{array}{l}
\text { No. of MM due to specific cause } \\
\text { in a specific year }
\end{array}}{\text { Total no. of MM in the same year }} \times 100
$$

No. of MM at certain stage (preg., labour

4. Proportion of MM by stage $=\frac{\begin{array}{l}\text { No. of MM at certain stage (preg., labour } \\ \text { or puerp.) in a specific year }\end{array}}{\text { Total no. of MM in the same year }} \times 100$

The significant changes in the trends of mortality and their causes were examined by Chi-squared test for Trend using Statdirect software program version 3. P-value $<0.05$ was considered statistically significant throughout data analysis.

\section{RESULTS}

Table 1 shows maternal mortality indicators including maternal mortality rates, maternal mortality ratios, and life time risk of maternal death. While maternal mortality rates were not changed significantly during the study period, maternal mortality ratios displayed the reverse state with $\mathrm{p}=0.002$. The situation was worsen in 2007 where highest levels of maternal mortality rates and ratios were recorded $(6.74 / 100,000$ women and $45.01 / 100,000$ live births respectively).

Life time risk of maternal death experienced a fluctuation in its trend with worsening during 2007 $(235 / 100,000$ women) and relieving in 2011 (83/100,000 women).

In Table 2 although there was unmistakable variation in the proportions of maternal mortality by stages of pregnancy, labour, and puerperium, however; $p$-values indicated non-significant changes in their trends throughout the study period.

Table 3 reveals that direct causes of maternal mortality formed the overwhelming proportion compared with indirect ones and they were responsible for $72.97 \%-96.15 \%$ of maternal deaths.

Hemorrhage whether antepartum or postpartum blamed to threat maternal lives and it was responsible for about a quarter to just more than half of all maternal deaths followed by hypertensive disorders of pregnancy (HDP), embolism, and obstructed labor. On the other hand, indirect causes formed small proportions among causes and were responsible for $3.85 \%$ $27.03 \%$ of maternal mortality predominated by cardiovascular diseases (CVDs). Most causes of maternal mortality showed non-significant changes throughout the study period although gathering direct and indirect causes portrayed significant changes in their trends with $p=0.006$ each, (Table 3 and Figure 1). 
Table 1. Trends of maternal mortality rates and ratios in Nineveh (2004-2013).

\begin{tabular}{|c|c|c|c|c|c|c|}
\hline Year & $\begin{array}{c}\text { No. of women } \\
(15-49) \text { years }\end{array}$ & $\begin{array}{l}\text { No. of live } \\
\text { births }\end{array}$ & $\begin{array}{c}\text { No. of } \\
\text { maternal } \\
\text { deaths }\end{array}$ & $\begin{array}{c}\text { MM rate } \\
/ 100,000 \\
\text { women }\end{array}$ & $\begin{array}{l}\text { MM ratio } \\
/ 100,000 \\
\text { live births }\end{array}$ & $\begin{array}{c}\text { Life time } \\
\text { risk of } \\
\text { maternal } \\
\text { death }^{\star}\end{array}$ \\
\hline 2004 & 559992 & 83717 & 21 & 3.75 & 25.08 & 131 \\
\hline 2005 & 580212 & 88916 & 22 & 3.79 & 24.74 & 132 \\
\hline 2006 & 599045 & 99137 & 31 & 5.17 & 31.27 & 181 \\
\hline 2007 & 638345 & 95526 & 43 & 6.74 & 45.01 & 235 \\
\hline 2008 & 665746 & 117067 & 26 & 3.91 & 22.21 & 136 \\
\hline 2009 & 670515 & 130244 & 32 & 4.77 & 24.57 & 167 \\
\hline 2010 & 723934 & 137775 & 37 & 5.11 & 26.86 & 179 \\
\hline 2011 & 719493 & 146040 & 17 & 2.36 & 11.64 & 83 \\
\hline 2012 & 733744 & 146864 & 26 & 3.54 & 17.70 & 124 \\
\hline 2013 & 756403 & 149297 & 31 & 4.10 & 20.76 & 143 \\
\hline P-value & ----- & ------ & ----- & 0.19 & 0.002 & ----- \\
\hline
\end{tabular}

*Measured for each 100,000 women at childbearing age (15-49 years).

Table 2. Trends of stages of maternal deaths in Nineveh (2004-2013).

\begin{tabular}{|c|c|c|c|c|c|c|c|}
\hline \multirow{3}{*}{ Year } & \multirow{3}{*}{$\begin{array}{c}\text { No. of } \\
\text { maternal } \\
\text { Deaths }\end{array}$} & \multicolumn{6}{|c|}{ Stages of Maternal Death } \\
\hline & & \multicolumn{2}{|c|}{ During pregnancy } & \multicolumn{2}{|c|}{ During labour } & \multicolumn{2}{|c|}{ During puerperium } \\
\hline & & No. & $\%$ & No. & $\%$ & No. & $\%$ \\
\hline 2004 & 21 & 6 & 28.57 & 10 & 47.62 & 5 & 23.81 \\
\hline 2005 & 22 & 4 & 18.18 & 9 & 40.91 & 9 & 40.91 \\
\hline 2006 & 31 & 6 & 19.35 & 9 & 29.03 & 16 & 51.62 \\
\hline 2007 & 43 & 9 & 20.93 & 20 & 46.51 & 14 & 32.56 \\
\hline 2008 & 26 & 5 & 19.23 & 16 & 61.54 & 5 & 19.23 \\
\hline 2009 & 32 & 11 & 34.38 & 12 & 37.50 & 9 & 28.12 \\
\hline 2010 & 37 & 9 & 24.32 & 9 & 24.32 & 19 & 51.36 \\
\hline 2011 & 17 & 7 & 41.18 & 1 & 5.88 & 9 & 52.94 \\
\hline 2012 & 26 & 6 & 23.08 & 15 & 57.69 & 5 & 19.23 \\
\hline 2013 & 31 & 8 & 25.81 & 12 & 38.71 & 11 & 35.48 \\
\hline P-value & ------ & ----- & 0.393 & ----- & 0.489 & ----- & 0.948 \\
\hline
\end{tabular}

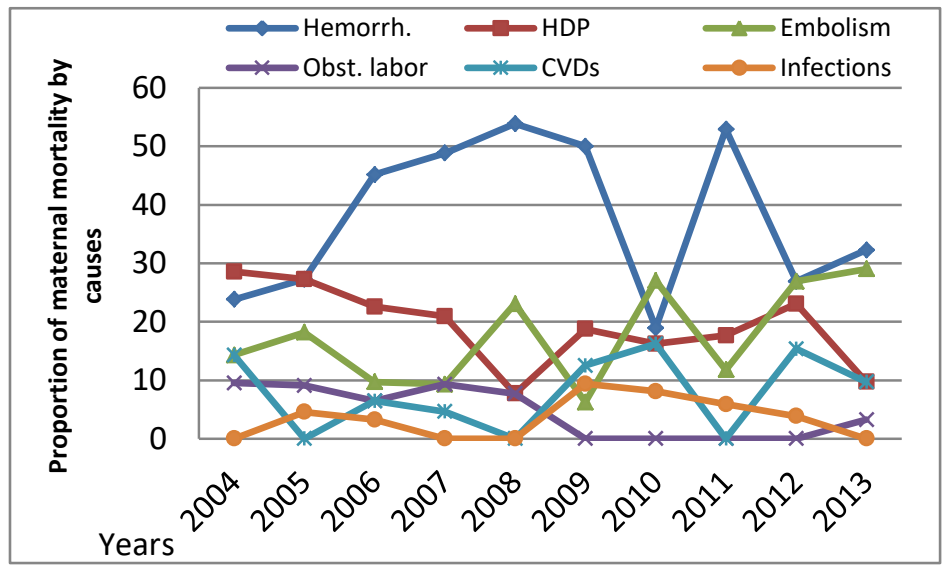

Figure 1. Trends of causes of maternal mortality in Nineveh (2004-2013). 
Table 3. Trends of causes of maternal mortality in Nineveh (2004-2013).

\begin{tabular}{|c|c|c|c|c|c|c|c|c|c|c|}
\hline \multirow{3}{*}{ Year } & \multicolumn{10}{|c|}{ Causes of maternal death in \% } \\
\hline & \multicolumn{6}{|c|}{ Direct obstetric causes } & \multicolumn{4}{|c|}{ Indirect causes } \\
\hline & $\begin{array}{l}\text { Hemorr- } \\
\text { hage }\end{array}$ & HDP & Embolism & $\begin{array}{l}\text { Obstructed } \\
\text { labour }\end{array}$ & Others & Total & CVDs & Infections & Others & Total \\
\hline 2004 & 23.81 & 28.57 & 14.29 & 9.52 & 9.52 & 85.71 & 14.29 & 0.00 & 0.00 & 14.29 \\
\hline 2005 & 27.27 & 27.27 & 18.18 & 9.09 & 13.64 & 95.45 & 0.00 & 4.55 & 0.00 & 4.55 \\
\hline 2006 & 45.16 & 22.58 & 9.68 & 6.45 & 3.23 & 87.10 & 6.45 & 3.23 & 3.23 & 12.90 \\
\hline 2007 & 48.84 & 20.93 & 9.30 & 9.30 & 6.98 & 95.35 & 4.65 & 0.00 & 0.00 & 4.65 \\
\hline 2008 & 53.85 & 7.69 & 23.08 & 7.69 & 3.85 & 96.15 & 0.00 & 0.00 & 3.85 & 3.85 \\
\hline 2009 & 50.00 & 18.75 & 6.25 & 0.00 & 3.13 & 78.13 & 12.50 & 9.38 & 0.00 & 21.88 \\
\hline 2010 & 18.92 & 16.22 & 27.03 & 0.00 & 10.81 & 72.97 & 16.22 & 8.11 & 2.70 & 27.03 \\
\hline 2011 & 52.94 & 17.65 & 11.76 & 0.00 & 0.00 & 82.35 & 0.00 & 5.88 & 11.76 & 17.65 \\
\hline 2012 & 26.92 & 23.08 & 26.92 & 0.00 & 0.00 & 76.92 & 15.38 & 3.85 & 3.85 & 23.08 \\
\hline 2013 & 32.26 & 9.68 & 29.03 & 3.23 & 3.23 & 77.42 & 9.68 & 0.00 & 12.90 & 22.58 \\
\hline $\begin{array}{c}\mathrm{P}- \\
\text { value }\end{array}$ & 0.551 & 0.104 & 0.026 & 0.011 & 0.109 & 0.006 & 0.226 & 0.526 & 0.004 & 0.006 \\
\hline
\end{tabular}

\section{DISCUSSION}

Globally, a substantial reduction in maternal deaths had been achieved in the past two decades from 543,000 deaths in 1990 to an estimated 287,000 by 2010 with an annual global reduction of $3.1 \%$, however; it still considered a global crisis in the current century ${ }^{13}$.

In the present study, maternal mortality rate was fluctuating insignificantly from 3.75 in 2004 to 4.1 in 2013 per 100,000 women at childbearing age, and the same, but significantly, was shown for maternal mortality ratio. The worst level of maternal death was during 2007 with maternal mortality rate and ratio of 6.74 and 45.01 respectively and the best was during 2011 , this may be due to the variation in security and economic statuses that made pregnant women seek management from different sites whether at home, birth attendants, or medical institutions. On average, each women had a risk of death of 1:666 or in other words, 1.5 for each 1000 women during maternity period approximating the global average life time risk in 2005 which was 1.13, with extremes of 5.42 and 0.01 in Sub-Saharan Africa and Europe respectively ${ }^{1}$.

Depending on the sources of mortality data, maternal mortality ratios in the present study were lower than the national levels reported by $\mathrm{WHO}^{(13)}$ in 2013 where their trend was reduced from 89 to 78 then to $63 / 100,000$ live births between 1990 , 2000 , and 2010 respectively which may result from the improvement in maternity services produced. These national ratios were in turn lower than the global average levels which were 110, 90, and $66 / 100,000$ live births in the same time period respectively with annual reduction rate of $2.6 \%$ as stated by Lawn et al. ${ }^{14}$.

During 2013, maternal mortality ratio was highest (250) in developing countries and lowest (16) in developed for each 100,000 live births ${ }^{4}$. The average life time risk of maternal death was 1:190 being worst $(1: 160)$ in developing and best $(1: 3700)$ in developed countries. The same document reported that, Iraq's maternal mortality ratio during 2013 was $67 / 100,000$ live births a little bit higher than its level in 2010 with a life time risk of $1: 340^{4}$.

Many countries made a good progress between 1990 and 2010 toward achieving their MDG5 through improving their maternity services like Bangladesh from 800 to 240 , China from 120 to $<40$, Egypt from 240 to 60 , Ethiopia from 960 to 350, Nepal from 790 to 190 , Peru from 200 to 65 , and Rwanda from 900 to 300 for each 100,000 live births ${ }^{15}$. However, the present study demonstrated maternal mortality levels approximating that of 
developed countries which may reflect the improved maternity health care services or could be an artifact as a result of under registration practices.

Exploring the causes of maternal mortality in the present work revealed that, 8-9 out of each 10 maternal deaths were attributed to direct causes among which hemorrhage was dominating and responsible for about a quarter to half of these deaths. On the other hand, HDP was the cause of another quarter of maternal mortality followed by embolism and obstructed labor. Of the indirect causes, CVDs were blamable for about $10 \%$ of maternal mortality followed by infections. Apart from embolism, the other major causes of maternal mortality were not changed significantly throughout the study period. Similarly, between 2003 and 2009, among the main causes of maternal mortality hemorrhage was the $1^{\text {st }}$ leading cause of death globally $(27 \%)$ followed by indirect causes including anemia, malaria, CVDs, tuberculosis, HIV/AIDS, and accidents (27\%), then HDP (14\%), sepsis $(11 \%)$, obstructed labor $(9 \%)$ abortion ( $8 \%)$, and embolism $(3 \%)^{16,17}$. Toward 2013, these causes changed greatly through which hemorrhage, HDP, and sepsis reduced, and unsafe abortion complications increased ${ }^{18}$. On the other hand, the indirect causes were also increased and became responsible for $40 \%$ of maternal mortality according to the 2011 statistics 19

Hemorrhage is one of the leading causes of maternal mortality in the present study and worldwide with a global prevalence rate of approximately 6\%. In Africa and Asia, where most maternal deaths occur, hemorrhage, especially postpartum, accounts for more than $30 \%$ of all maternal mortality ${ }^{20}$. Sepsis, on the other hand, accounted for $10.7 \%$ of maternal deaths from 2003 to 2012 according to the WHO systematic analysis on the global causes of maternal death ${ }^{21}$.

The higher contribution of hemorrhage and very little share of the indirect causes on maternal death in the present study may be related to the shortage in the maternity services that incapacitating the increased levels of fertility, adding to that, the uncommon prevalence of infectious diseases like AIDS, malaria, and tuberculosis in the present study locality make these indirect causes to have no any impact on maternal mortality compared with other developing countries.

Despite the global progress on reducing maternal mortality, most countries were unable to meet their MDG5 target and Iraq is one of them ${ }^{(12)}$. There is still a lot to be done to improve the national health care systems including maternity services in particular in order to end maternal preventable deaths.

\section{CONCLUSIONS AND RECOMMENDATIONS}

Low levels of maternal mortality rates and ratios are documented in the present study, however; increasing medical institutions and designing programs for home-based deliveries by skilled birth attendants who are educated and trained to proficiency in the skills of managing normal and complicated pregnancies with adequate referral are recommended in a try to overcome the high fertility levels and reduce maternal deaths.

\section{REFERENCES}

1.Wilmoth J. The lifetime risk of maternal mortality: Concept and measurement. Bull World Health Organ 2009; 87:256-262.

2.Lwanga SK, Cho-YT, Ayeni O. Teaching health statistics: lessons and seminars outlines. WHO, Geneva, 1999.

3.World Health Organization. Catalogue of health indicators: A selection of important health indicators recommended by WHO programs. Unit of strengthening country health information, division of health situation and trend assessment. Geneva, 1996.

4.World Health Organization, UNICEF, UNFPA, The World Bank, United Nations Population Division. Trends in maternal mortality: 1990 to 2013. WHO, 2014.

5.World Health Organization. World health statistics. WHO Department of Health Statistics and Information Systems of the Health Systems and Innovation Cluster, Geneva, Switzerland, 2009.

6.Fighting against maternal and neonatal mortality in developing countries. The Sanofi Espoir Foundation, Press kit; 2014.

7.Goldenberg RL and McClure EM. Maternal mortality. Am J ObstetGynecol 2011; 205(4):293-295.

8.King JC. Maternal mortality in the United States: why is it important and what are we doing about it? Elsevier Inc. Semin Perinatol 2012; 36:14-18.

9.Graham $\mathrm{W}$ and Filippi $\mathrm{V}$. Monitoring maternal health goals: How well do the indicators perform? Technical working group on indicators to monitor maternal health goals, Geneva, WHO, 1993.

10.Population of Nineveh. Nineveh Health Directorate, Statistical Department, 2013.

11.Al-Khafajei AMB. Problem- based learning in epidemiology: Simulated exercise from the practice of public health medicine, 1998. 
12.Population of Nineveh. Nineveh Health Directorate, Statistical Department, 2013.

13.World Health Organization. World health statistics. WHO Department of Health Statistics and Information Systems of the Health Systems and Innovation Cluster, Geneva, Switzerland, 2013.

14.Lawn JE. Newborn survival: A multi-country analysis of a decade of change. Health Policy and Planning 2012; 27(3):6-28. Data sources: UNICEF 2012 and WHO MMR estimates 2014.

15.Options Consultancy Services/Evidence for Action, Cambridge Economic Policy Associates, and the Partnership for Maternal, Newborn and Child Health. Success factors for women's and children's health: Country specific review of data and literature on 10 fasttrack countries' progress towards MDGs 4 and 5, 2013.

16.Kassebaum NJ, Bertozzi-Villa A, Coggeshall MS, Shackelford KA, Steiner C. Global, regional, and national levels and causes of maternal mortality during 19902013: A systematic analysis for the Global burden of disease study 2013. Lancet 2014; 384(9947):980-1004.
17.World Health Organization. Strategies toward ending preventable maternal mortality. WHO, UNICEF, UNFPA, USAID, FEGO, WRA, World Bank, and other related agencies, 2015.

18.Global Burden of Diseases, Mortality and Causes of Death Collaborators. Global, regional, and national agesex specific all-cause and cause-specific mortality for 240 causes of death, 1990-2013: A systematic analysis for the Global Burden of Disease Study 2013. Lancet 2014; 385: 117-71.

19.Gaul A, Bliss L, Fridirici H, Zambra C, Marshall K. Reducing maternal mortality: Actual and potential roles for faith-linked institutions and communities, religion and global development. Berkley center for religion, peace and world affairs at Georgetown university, 2011.

20.Fawole B, Awolude OA, Adeniji AO, Onafowokan O. WHO recommendations for the prevention of postpartum hemorrhage: RHL guideline. The WHO Reproductive Health Library; Geneva: WHO, 2010.

21.Say L, Chou D, Gemmill A. Global causes of maternal death: a WHO systematic analysis. Lancet Glob Health 2014;2(6):e323-33. 